\title{
ASYMMETRY OF COMPLEX REACTION TIME IN FEMALE ÉPÉE FENCERS OF DIFFERENT SPORTS CLASSES
}

\author{
MONIKA JOHNE ${ }^{1}$, TATIANA POLISZCZUK ${ }^{2}$, DMYTRO POLISZCZUK ${ }^{1}$, \\ AGNIESZKA DĄBROWSKA-PERZYNA ${ }^{3}$
The Jozef Pilsudski University of Physical Education in Warsaw, Faculty of Physical Education, Department of Physiology¹, Department of Gymnastics and Sport for All', Department of Physical Games and Activities and Dance ${ }^{3}$

\author{
Mailing address: Monika Johne, The Jozef Pilsudski University of Physical Education in Warsaw, \\ Department of Physiology, 34 Marymoncka Street, 00-968 Warszawa, \\ tel.: +48 2283422 25, fax: +48 22 8651080, e-mail: monika.johne@awf.edu.pl
}

\begin{abstract}
Introduction. The issue of asymmetry is becoming more and more widespread, causing considerable difficulties for sportspersons. The aim of this study was to assess dynamic asymmetry of complex reaction time in female épée fencers from different sports classes. Material and methods. Study participants comprised 45 female fencers divided into 3 groups. The RT-S5 test of the Vienna Test System was used to record reaction time and motor time in response to visual and audiovisual stimuli. Conclusions. The study found differences in complex reaction time between fencers of different sports classes. Champion-class fencers showed a very high dynamic asymmetry. Considerable differences in complex reaction time were found depending on the type of stimulus involved.
\end{abstract}

Key words: dynamic asymmetry, complex reaction time, fencing, Vienna Test System

\section{Introduction}

The issue of morphological and dynamic asymmetry is becoming more and more widespread in sports, causing considerable difficulties for sports persons. These difficulties are often overlooked or neglected by trainers. Unilateral training frequently makes it impossible for the trainee to perform well in sports. Contemporary sport involves physical strain that, combined with an excessive number of asymmetrical exercises, leads to numerous injuries, such as bone cysts, deformations of joints and the spine, and increased cross-section of muscles [1]. Many athletes suffer from detrimental changes that fairly quickly eliminate them from sport for ever. "Contemporary competitive sport as well recreational sport must not deform, let alone incapacitate" [2]. We frequently witness a premature end to the careers of promising sportspersons, who at a young age experience health problems resulting from an excess of asymmetrical exercise. This study assesses the degree of dynamic asymmetry based on complex reaction time.

In fencing, the ability to react quickly is a major factor in determining performance. Experienced fencers recognize their opponent's intentions by noting initiating actions, such as flexing shoulder muscles or flexing the muscles of the supporting leg. However, the more skilled the opponent, the better they are at coordinating their own movements and the more difficult it is to recognize their intentions and, consequently, to prepare for defensive actions [3]. These factors depend primarily on the fencer's experience, which is why fencers are very often most successful at the ages of 25-35 years.

Simple reactions are predominant in the constantly changing conditions of a sports duel, but the complex reaction time of fencers is becoming more and more important. According to
Czajkowski, "A whole plethora of excellent, world-class fencers can be named whose movements were not particularly quick, but whose reactions were extremely accurate" [4].

One should also consider differences in reaction time depending on the type of stimulus involved. In addition to visual stimuli, touch ("feeling the iron") also plays a vital role in fencing; however, the importance of touch in fighting is unfortunately decreasing, especially in épée fencing. This is caused by a shift away from complex technique and towards speed-based actions and simple actions, with limited "contact with the iron." Aural stimuli in conjunction with visual stimuli also play a certain role: for example, in elements of legwork such as jumping forward to close the distance to the opponent or the rhythm of steps [5].

The aim of this study was to assess dynamic asymmetry in terms of complex reaction time in female épée fencers of different sports classes.

\section{Material and methods}

Study participants comprised $\mathrm{N}=45$ female épée fencers divided into 3 groups (Tab. 1).

Group I comprised $n=15$ champion-class and international champion-class fencers. These fencers, who are part of the primary representation of Poland, have won medals at Polish, European, and World Championships.

Group II comprised $n=15$ fencers belonging to the first sports class. These fencers were medal winners at the Polish Championship and are part of the representation of Poland.

Group III comprised $n=15$ fencers belonging to the second sports class, who are members of the Legia Warszawa sports club. 
All assessments were conducted during the competitive phase of the mesocycle.

Table 1. Characteristics of the groups $(\overline{\mathrm{x}} \pm \mathrm{SD})$

\begin{tabular}{|l|c|c|c|}
\hline \multicolumn{1}{|c|}{ Index } & Group I $(\mathrm{n}=15)$ & Group II $(\mathrm{n}=15)$ & Group III $(\mathrm{n}=15)$ \\
\hline Age [years] & $21.9 \pm 3.5$ & $18.1 \pm 2.3$ & $15.5 \pm 1.3$ \\
\hline Body height [cm] & $176 \pm 6.6$ & $173.7 \pm 5.7$ & $168.3 \pm 5.3$ \\
\hline Body weight [kg] & $65.1 \pm 7.1$ & $60.7 \pm 6.9$ & $57.1 \pm 6.5$ \\
\hline Training intership [years] & $11.5 \pm 3.6$ & $7.8 \pm 2.2$ & $3.4 \pm 1.1$ \\
\hline Sports class & Ch, ICh & I & II \\
\hline
\end{tabular}

Key: Ch - champion sports class, ICh - international champion sports class,

I - first sports class, II - second sports class

The study was performed using the Vienna Test System (VTS) that allows for the evaluation of physiological and motor coordination abilities and for the neuropsychological predispositions that determine coordination of human movements [6].

Complex reaction time was measured using the RT (Reaction Time) test in the S5 form and a device that generated visual stimuli (appearing on the monitor) and audiovisual stimuli. The test lasted 10 minutes for each upper limb. To assess the results, special software was used that measured individual reaction times, which in turn were used to calculate reaction time [ms] (the time between the stimulus appearing and the participant releasing the "rest key") and motor time [ms] (the time between the participant releasing the "rest key" and pressing the "reaction key"). The measurement was performed using the dominant and the non-dominant upper limbs.

Statistical analysis of the results was performed using the STATISTICA software (StatSoft, Inc., 2001). The normality of statistical distributions was assessed using the Shapiro-Wilk test. Analysis of variance (ANOVA) was applied to compare results of measurements between the three groups. Statistical significance was set at $\alpha=0.05$.

\section{Results}

The study found considerable differences between the three groups in the mean values of measured indicators of the speed of complex reaction, i.e., the complex reaction time and motor time of the complex reaction obtained using the dominant and the non-dominant upper limbs (Tab. 2).

Table 2. Values of indicators of complex reaction speed achieved using the dominant and non-dominant upper limbs by fencers of different sports classes ( $\overline{\mathrm{x}} \pm \mathrm{SD}$ ), $\mathrm{N}=45$

\begin{tabular}{|l|c|c|c|}
\hline \multicolumn{1}{|c|}{ Index } & Group I $(\mathbf{n}=15)$ & Group $I I(\mathbf{n}=15)$ & Group III $(\mathbf{n}=15)$ \\
\hline CRT DL [ms] & $391.1 \pm 34.5$ & $435.4 \pm 28.3$ & $470.5 \pm 50.16$ \\
\hline CRT NDL [ ms] & $424.7 \pm 45.9$ & $427.9 \pm 47.6$ & $453.5 \pm 43.7$ \\
\hline$M T C R$ [ $[\mathrm{ms}]$ & $94.9 \pm 14.1$ & $94.3 \pm 26.1$ & $106.3 \pm 35.7$ \\
\hline MTCR NDL [ms] & $107.9 \pm 19.1$ & $104.1 \pm 30.7$ & $115.2 \pm 18.6$ \\
\hline
\end{tabular}

Key: CRT DL - complex reaction time of the dominant limb, CRT NDL - complex reaction time of the non-dominant limb, MTCR DL - motor time of the complex reaction of the dominant limb, MTCR NDL - motor time of the complex reaction of the non-dominant limb.

The study found differences in the mean values of complex reaction time of fencers in different sports classes. Significant differences in complex reaction time of the dominant limb were noted between champion-class fencers and fencers of both the first and second classes. Differences were also found between groups II and III. These results signify a great role of complex reaction time in achieving success in fencing (Tab. 3 ).

Table 4 presents significant differences in motor time of the complex reaction using the dominant upper limb. These differences were found only between groups I and II. The values of the complex reaction time of the non-dominant limb were significantly different between group I and fencers of the second sports class. Furthermore, the study found no significant differences in motor time of the non-dominant limb between fencers of different sports classes.

Table 3. Differences between parameters of complex reaction time using the dominant and non-dominant limbs in fencers of different sports classes, $\mathrm{N}=45$

\begin{tabular}{|c|c|c|c|}
\hline The study groups & Group I & Group II & Group III \\
\hline Group I & & $* *$ & $* *$ \\
\hline Group II & & & $*$ \\
\hline Group III & a & & \\
\hline
\end{tabular}

* statistically lower compared to group II; dominant limb $(\mathrm{p}<0.03)$

** statistically lower compared to group I; dominant limb $(\mathrm{p}<0.01)$

a - statistically lower compared to group III; non-dominant limb $(\mathrm{p}<0.001)$

Table 4. Differences in parameters of motor time of complex reaction using the dominant and non-dominant limb between fencers of different sports classes, $\mathrm{N}=45$

\begin{tabular}{|c|c|c|c|}
\hline The study groups & Group I & Group II & Group III \\
\hline Group I & & & $*$ \\
\hline Group II & & & $* *$ \\
\hline Group III & & & \\
\hline
\end{tabular}

* statistically lower compared to group I; dominant limb $(\mathrm{p}<0.03)$

** statistically lower compared to group II; dominant limb $(\mathrm{p}<0.005)$

Each group displayed considerable differences in dynamic asymmetry of upper limbs. Differences in parameters of complex reaction time using the dominant and non-dominant limb, shown in Figure 1, confirm a considerable motor asymmetry in fencers of the champion-class. On the other hand, fencers in groups II and III showed no significant dynamic asymmetry in terms of complex reaction time.

Values of motor time of the complex reaction using the dominant and non-dominant limbs were significantly different only in group I. This indicates a major dynamic asymmetry in fencers of the champion class, which is probably the result of long-term unilateral training. Other parameters of complex reaction time using the dominant and non-dominant limbs were not statistically different (Fig. 2). 


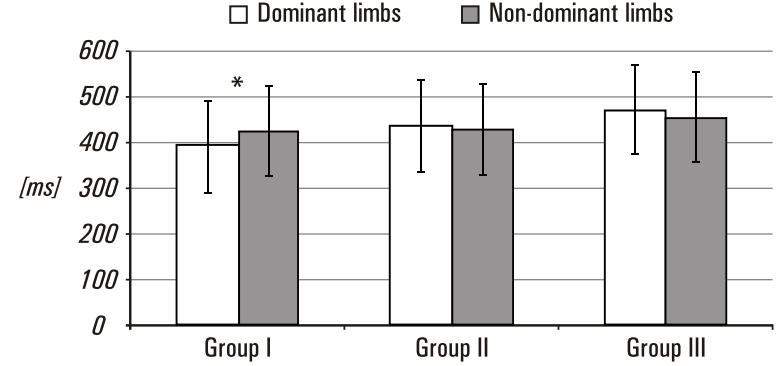

Figure 1. Mean $( \pm \mathrm{SD})$ complex reaction time $[\mathrm{ms}]$ of the dominant and non-dominant limbs in fencers of different sports classes

* statistically lower compared to the non-dominant limb $(\mathrm{p}<0.03)$

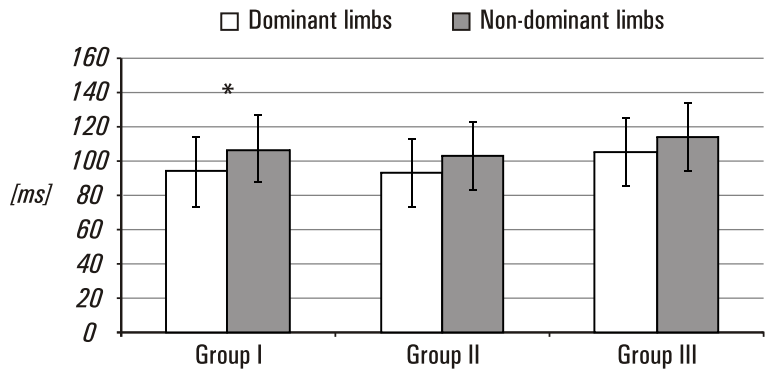

Figure 2. Mean $( \pm \mathrm{SD}$ ) complex reaction time $[\mathrm{ms}]$ of the dominant and non-dominant limbs in fencers of different sports classes

* statistically lower compared to the non-dominant limb $(\mathrm{p}<0.03)$

Assessing complex reaction time also requires analyzing the number of incorrect and incomplete reactions. Measurements using the RT-S5 test allowed us to register the number of incorrect, incomplete, and missing reactions to a given stimulus. Whether a fencing duel or in the performed test, it is the appropriate reaction, not speed, which is crucial. A fencer will not be able to even land a very quick strike if they fail to recognize their opponent's true intentions.

Despite the fact that champion-class fencers have the quickest reactions, they also showed the smallest number of incorrect reactions $(0.43 \pm 0.65)$ when using their dominant limb, with no missing or incomplete reactions.

Fencers in group II also showed no incomplete reactions, but had a small number of incorrect $(0.53 \pm 0.92)$ and missing reactions $(0.13 \pm 0.52)$.

Fencers in group III showed the highest number of incorrect $(0.60 \pm 1.12)$, incomplete $(0.13 \pm 0.52)$, and missing reactions $(0.33 \pm 0.72)$.

Champion-class fencers, despite a small number of incorrect reactions (the smallest number of all three groups), showed a very good complex reaction time using the dominant limb.

Reactions performed using the non-dominant limb showed similar results. Champion-class fencers had the shortest complex reaction time, with the smallest number of incorrect reactions $(0.27 \pm 0.46)$ and no missing reactions.

Fencers of the first sports class showed no incomplete reactions, but had some missing $(0.13 \pm 0.35)$ and incorrect reactions $(0.47 \pm 0.99)$.

Fencers in group III had a longer complex reaction time, with $0.60 \pm 0.82$ missing reactions, $0.13 \pm 0.36$ incomplete reactions, and $0.47 \pm 0.99$ incorrect reactions. Differences in values of complex reaction time were found when the type of stimulus was considered. Study participants reacted the fastest to audio- visual stimulus. Significant differences $(\mathrm{p}<0.05)$ in complex reaction time in response to audiovisual and visual stimuli using the dominant limb were found in all three groups. Even greater $(\mathrm{p}<0.001)$ differences in these parameters were found for the non-dominant hand $(\mathrm{p}<0.0001)$.

\section{Discussion}

Coordination abilities play a key role in achieving high performance in sports [7, 8]. Researchers agree that reaction time is important for sportspersons engaging in fighting sports if they are to be successful $[9,10]$. Many studies on reaction time in various sports disciplines were based on its two indicators: motor time and choice reaction time. These indicators were treated as the main source of information when assessing speed abilities $[11,12,13]$. Studies were also conducted on lateral differences in reaction time. Studies on dynamic asymmetry most often used very simple tests that measured limb strength [14].

Measuring reaction time and motor time separately is important in practical terms, as it helps determine time-based connections between constituents of information processes when assessing individual abilities of fencers of different sports classes. Inexperienced fencers react differently than experienced fencers. The former analyze information in the sensory phase much longer than the latter, compensating for the prolonged central phase by quickly performing the movement itself. On the other hand, champion fencers, drawing from their experience, significantly shorten their decision-making time by using their anticipatory abilities [15].

The results of this study indicate that a significant difference occurs already between female fencers of the champion sports class and of the first sports class. Fencers with greater training experience displayed a shorter reaction time. However, the group showed a considerable dynamic asymmetry that could impede future development of this coordination ability.

Similar to research done by Borysiuk [16] on sportspersons engaged in taekwondo, karate and fencing, the obtained results indicate a significant change in the relationship between reaction time and motor time. We have concluded that reaction time can be significantly shortened, whereas motor time remains at similar levels. This fact unambiguously indicates that trainers of fighting sports should introduce changes to the training curriculum.

Study results show that fencers very often achieve better complex reaction time when they use their non-dominant upper limb, as was the case in groups II and III. The best complex reaction time was achieved by left-handed fencers. Assessment of champion-class fencers found that training experience and a narrow specialization contribute to achieving a shorter complex reaction time.

Fencing trainers often point to laterality as an important factor in achieving high performance [17]. Initially, the unusual character of a duel against a left-handed fencer or a lack of individual training with a left-handed trainer plays a major role. Other studies indicate that better performance by left-handed fencers can be the result of their shorter reaction time [18].

Jefimow and Kurpijanow reached a similar conclusion after assessing 60 persons aged 16-18 years who trained fighting sports [19]. The authors showed that left-handed sportspersons are quicker than right-handed sportspersons and that the quality of technique improves with the increase in motor symmetry.

This study found a significant difference in complex reaction time between group I and groups II and III, as well as between group II and group III. These results show that complex reaction time plays a very important role in achieving high performance in fencing. Significant differences in mean motor time were only found between groups I and III. 
Klapp showed that reaction time is not always the same and that the complexity of movement in choice reaction does not necessarily prolong the latency phase [20].

Fencers employ different actions depending on the simple and complex reaction time. For instance, a fencer with a very quick simple reaction employs considerably more actions based around the reception of a particular stimulus, such as a simple fleche. Such actions pose a smaller risk and are used more and more often in épée fencing. Conversely, fencers with good reactions choose to employ many more complex actions that do not provide obvious clues to the fencer's intentions and which they frequently change throughout the duel. Such actions are extremely difficult to perform and their effectiveness depends not only on the fencer's technique and complex reaction, but also on the opponent's reaction. Experienced fencers recognize their opponent's intentions by noting initiating actions. Because they are well trained, they display optimal alertness, focus, and an extraordinary accuracy of response to the opponent's actions. Other researchers [21] have reached similar conclusions, stating that fencers with a extensive training experience shorten decision-making time by incorporating anticipatory factors. On the other hand, less experienced fencers process information in the sensory phase. This takes more time. This thesis is also supported by the results of this study. Champion-class fencers, despite not having trained with their non-dominant limb, performed better in terms of complex reaction time than fencers of the first sports class who used their dominant hand. Champion-class fencers showed a very high dynamic asymmetry despite their excellent results in the test involving the non-dominant arm.

The study found differences in complex reaction time depending on the type of stimulus involved. The three groups showed significant differences in complex reaction time in response to audiovisual and visual stimuli, both for the dominant and the non-dominant limb.

These results are consistent with the findings of Kandel, Shwarz and Jessel [22], who claim that reaction time in response to tactile and aural stimuli is the shortest, which is due to a quick processing of information by aural receptors and a rapid relaying of the afferent impulse to the brain.

Borysiuk reached a similar conclusion after performing a study with athletes engaged in fighting sports. He stated that the athletes react much faster to aural and tactile stimuli than to visual stimuli [5].

The results of this study may contribute to a modification to the planning and scheduling of fencing training on all stages that would incorporate the complex reaction time of the fencers.

\section{Conclusions}

1. Fencers of different sports classes display differences in complex reaction time. Fencers of a higher class had a shorter complex reaction time.

2. Champion-class fencers show a high dynamic asymmetry of the upper limbs in terms of complex reaction compared to less experienced fencers.

3. Significant differences were found in complex reaction time depending on the type of stimulus involved. Fencers react the fastest to audio-visual stimuli.

\section{Acknowledgments}

The research was accomplished within the framework of statutory research of the Josef Pilsudski University of Physical Education in Warsaw - DS. 175 - financed by the Ministry of Science and Higher Education.

\section{Literature}

1. Starosta W. (1996). Symetrization of movements: a method of developing coordination in beginner and advanced athletes. Sport Wyczynowy 7-8, 36-47. [in Polish]

2. Starosta W. (2003). Motor Coordination Abilities: their role, structure, conditions, and development. Warszawa: Instytut Sportu. [in Polish]

3. Starkes J.L., Ericsson K.A. (2003). Expert performance in sports. Champaign: Human Kinetics.

4. Czajkowski Z. (1998). Relationships between sensorimotor reactions and programming and complexity of movement. Sport Wyczynowy 3-4, 27-30. [in Polish]

5. Rhodes R.E., Courneya K.S., Hayduk L.A. (2002). Does personality moderate the theory of planned behavior in the exercise domain. Journal of Sport and Exercise Psychology 1, 5-62.

6. Schuhfried G., Prieler J. (2001). Wiener Reactions test. Version 27.00. Möedling, Germany: Dr G. Schuhfried Ges. m. b.H.

7. Lyakh V., Sadowski J., Witkowski Z. (2011). Development of coordination motor abilities (CMA) in the system of longterm preparation of athletes. Polish Journal of Sport and Tourism 18(3), 187-196.

8. Sadowski J., Niźnikowska E., Niźnikowski T. (2009). Effectiveness of teaching the basic acrobatic exercises and patterns in the case acrobats having different coordination potential. Polish Journal of Sport and Tourism 16(4), 209-220.

9. Mouelhi Guizani S., Bouzaouach I., Tenenbaum G., Ben Kheder A., Feki Y., Bouaziz M. (2006). Simple and choice reaction times under varying levels of physical load in high skilled fencers. The Journal of Sports Medicine and Physical Fitness 46(2), 344-351.

10. Roi G.S., Pittaluga I. (1997). Time-motion analysis in women's sword fencing. In $4^{\text {th }}$ IOC Congress on Sport Sciences, 22-25 October 1997. Principality of Monaco.

11. Viitasalo J.T., Komi P.V. (2008). EMG, reflex and reaction time components, muscle structure, and fatigue during intermittent isometric contractions in man. International Journal of Sports Medicine 1(4), 185-190. DOI: 10.1055/s-20081034657.

12. Gursoy R., Aggon E., Stephens R., Mehmet A.Z.(2012). Comparison of the physical and biomotor characteristics, and reaction time between Turkish male and female ice hockey players. Advances in Physical Education 2(4), 69-171. DOI: 10.4236/ape.2012.24029.

13. Rodrigues P., Barbosa R., Carita A.I., Barreiros J., Vasconcelos O. (2012). Stimulus velocity effect in a complex interceptive task in right - and left - handers. European Journal of Sport Science 12(2), 130-138. DOI:10.1080/17461391. 2010.546059.

14. Struzik A., Pietraszewski B. (2010). Examination of the relationship between the static moment of force and the height of Counter Movement Jump. Acta Bio-Optica et Informatica Medica. Inżynieria Biomedyczna 16(4), 346-350.

15. Borysiuk Z. (2006). Time Structure of Information Processes in Selected Fighting Sports. Warszawa: AWF. [in Polish]

16. Borysiuk Z. (2006). Complex evaluation of predispositions of fencers in three stages of sport development. Biology of Sport 1, 41-55.

17. Poliszczuk T., Lampkowska M. (2007). Functional and dynamic asymmetry of simple reaction time in female fencers. Pediatric Endocrinology, Diabetes and Metabolism 13(3), 7982.

18. Grabowska A. (1994). Left-handedness and lateralization of visual-spatial functions in the brain. Przeglad Psychologiczny 3, 301-312. 
19. Jefimowa I.W., Kuprijanow W.A. (1995). Functional asymmetry and its importance in sports practice. Teoria i Praktika Fiziczeskoj Kultury 2, 23-24. [in Russian]

20. Klappa S.T. (1996). Reaction time analysis of central motor control. In H. N. Żelaźnik (Ed.), Advances in motor learning and control (pp.3, 24-29). Champaing: Human Kinetics.

21. Williams L.R., Walmsley A. (2000). Response timing and muscular coordination in fencing: a comparison of elite and novice fencers. Journal Science and Medicine in Sport 3, 460-475.
22. Kandel E.R., Schwarz J.H., Jessell T.M. (2000). Principals of neural science. New York: McGraw-Hill.

Submitted: December 6, 2012

Accepted: January 25, 2013 